\title{
Potential markers of heavy training in highly trained distance runners
}

\author{
T. Verde PhD, Scott Thomas PhD and Roy J. Shephard MD, PhD, DPE \\ School of Physical and Health Education and Graduate Programme in Exercise Sciences, University of Toronto, \\ Canada
}

\begin{abstract}
Markers of a heavy increase in training were examined in ten highly trained distance runners (mean(s.d.) age $29.8(1.7)$ years, maximal oxygen intake $65.3 \mathrm{ml} \mathrm{kg}^{-1} \mathrm{~min}^{-1}$, personal best $10-\mathrm{km}$ time $31 \mathrm{~min} 4 \mathrm{~s}$ ) who undertook a deliberate $38 \%$ increment of training over a 3-week period. Their running performance did not improve, and six of the ten subjects developed sustained fatigue, suggesting that training was excessive, although the full clinical picture of overtraining did not develop. The Profile of Mood States was the best single marker of disturbed function, indicating increased fatigue and decreased vigour. There were no useful changes of resting heart rate or perceived exertion during submaximal running, sleep was undisturbed, and there were no orthopaedic injuries. Two subjects developed rhinoviral infections following the heavy training, and a third complained of symptoms that were diagnosed 2 weeks later as exercise-induced asthma. The increase of serum cortisol normally induced by $30 \mathrm{~min}$ of submaximal exercise was no longer seen when the same acute exercise was performed after heavy training. Resting lymphocyte proliferation tended to increase in response to phytohaematoglutinin (PHA) and concanavalin A (Con A), the ratio of helper to suppressor cells (H/S) decreased, and pokeweed mitogen induced smaller increases in IgG and IgM synthesis. Whereas before heavy training, PHAstimulated lymphocyte proliferation was unchanged by $30 \mathrm{~min}$ of acute submaximal exercise, after 3 weeks of heavy training the same bout of exercise caused an $18 \%$ suppression of proliferation. Likewise, heavy training brought about a decrease of T-lymphocytes in response to acute submaximal exercise, but an abolition of the acute exercise-induced decrease in the $H / S$ ratio. The previously observed exercise-induced decrease of IgG synthesis did not occur when the same acute bout of exercise was performed after heavy training. We conclude that such minor and transient changes of immune function may possibly be a warning that training is becoming excessive, but they have only a limited significance for overall immune function.
\end{abstract}

Keywords: Heavy endurance training, staleness, stress reactions, overtraining, immune system, immune function, immunoglobulins, lymphocyte proliferation, helper/ suppressor cell ratios, cortisol, creatine kinase

Address for correspondence: Professor Roy J. Shephard, School of Physical and Health Education, 320 Huron Street, Toronto, Ontario M5S 1A1, Canada

(C) 1992 Butterworth-Heinemann Ltd 0306-3674/92/030167-09
Athletic coaches are all too familiar with the situation of excessive training, characterized by a long-lasting fatigue and worsening of competitive performance with further attempts to improve physical condition ${ }^{1}$. The phenomenon has been described, more or less interchangeably, by a multitude of descriptive terms, including staleness, overreaching, overwork, burnout, chronic fatigue and overstress, as well as overtraining. Diagnosis of the fully developed condition is commonly based on clinical findings, including a decrease of appetite, weight loss, a slow recovery after an exercise bout, increased irritability or emotional lability, and disturbed sleep patterns ${ }^{2}$. Dressendorfer et $a l .^{3}$ have reported an increase of heart rate, although their subjects did not show any deterioration of performance. Other authors have not consistently confirmed this observation in athletes with clearer evidence of overtraining ${ }^{2}$. The precise contributions of physiological, biochemical, psychological and pathological changes to the observed clinical syndrome are still unclear, and there is no good agreement on biological markers that can be used to maximize competitive preparation while avoiding overtraining.

Although anaemia, a negative nitrogen balance, a lack of specific amino acids such as glutamine, glycogen depletion, chronic electrolyte depletion and repeated subclinical injuries might all be suspected as potential contributing factors, standard blood chemistry data such as haemoglobin and serum protein concentrations, serum electrolyte levels and muscle enzyme activities have failed to demonstrate any striking changes in affected competitors ${ }^{2,4,5}$. Some authors have associated excessive training and/or staleness with allergic reactions, head colds and other infections ${ }^{6-8}$ but it has been less clear whether this is a cause or an effect of the overtraining syndrome. One plausible hypothesis is that heavy training depresses immune function, leaving the body more vulnerable to infection ${ }^{6,9-12}$. This in turn suggests the possibility of detecting excessive training in terms of immune reactions to exercise.

We have further explored reactions to heavy training in a group of ten competitive distance runners who were well-trained initially. They were normally running $70-100 \mathrm{~km}$ per week, and for the purpose of the experiment they volunteered to increase their training volume by an average of $38 \%$ for a 3-week period. We studied various measures of 
immune function and other potential markers of excessive training initially, at the end of the 3 weeks of heavy training, and after subjects had repeated 3 weeks of their baseline training. Since lymphocytes are considered the most important link in the relationship between exercise and immune function ${ }^{13,14}$ we elected to make in vitro assessments of mitogen-stimulated lymphocyte proliferation rates, percentages of $T$ and $B$ cells, helper: suppressor cell ratios and the capacity of specimens to synthesize immunoglobulins.

\section{Subjects and methods}

The subjects for this investigation were all volunteers, ten highly trained male distance runners of mean(s.d.) age 29.8(1.7) years who had been recruited and tested in accordance with a protocol approved by the University of Toronto Committee on Human Experimentation. All had achieved a $10-\mathrm{km}$ performance of $<35 \mathrm{~min}$ within the preceding 12 months. Their mean(s.d.) personal best speed of $4.76(0.26) \mathrm{m} \mathrm{s}^{-1}$ for the $10-\mathrm{km}$ distance may be compared with national and world records of 5.98 and $6.14 \mathrm{~m} \mathrm{~s}^{-1}$. We did not feel ethically justified in driving the group into the extreme state of chronic fatigue and exhaustion typical of clinical 'overtraining', but nevertheless the subjects each agreed to undertake a substantial increase over their normal training routine for a 3-week experimental period, boosting their training volume to the maximum that they judged compatible with a consistent 3-week effort while avoiding major injuries. The consensus of the group was that they could sustain a $25 \%$ increment for the 3-week period. Compliance was monitored by detailed activity questionnaires, and in fact the average increase of training volume was $38 \%$.

All subjects made five visits to the laboratory at a personally consistent time of day, usually in the late afternoon. Visits 1 and 2 followed 3 weeks of adherence to their normal training plan, visits 3 and 4 were made after 3 weeks of deliberately increased training, and visit 5 followed 3 weeks of reversion to the original training schedule. We wished to examine acute exercise responses as soon as immune function had recovered from the daily training sessions. The usual recovery period is less than $24 \mathrm{~h}$, and accordingly we requested subjects to limit their training to low distance and low intensity work for $36 \mathrm{~h}$ immediately preceding each of the laboratory visits. During visits 2,3 and 5, activity and sleep questionnaires ${ }^{15}$ plus the Profile of Mood States questionnaire $^{16}$ were completed, anthropometric measurements were made, and the maximal oxygen intake was determined by uphill treadmill running. On day 2 of each visit, subjects ran for $30 \mathrm{~min}$ at $80 \%$ of their personal maximal oxygen intake, with blood samples being collected before and $5 \mathrm{~min}$ and $30 \mathrm{~min}$ after the acute exercise bout.

\section{Maximal oxygen intake determinations}

Subjects were tested by a progressive treadmill run to exhaustion. After a 3-min warm-up $\left(9.6 \mathrm{~km} \mathrm{~h}^{-1}, 0 \%\right.$ slope), the treadmill speed was increased to a steady
$14.5 \mathrm{~km} \mathrm{~h}^{-1}$, with a $2 \%$ increase of slope every $2 \mathrm{~min}$. Expired gas was collected and analysed using a Beckman Metabolic Cart (Beckman Instruments, Malton, Ontario, Canada). The heart rate $\left(\mathrm{CM}_{5}\right.$ electrode placement) was recorded during the final $10 \mathrm{~s}$ of each test minute.

Three criteria were used in gauging maximal effort: a plateau of oxygen consumption to within $2 \mathrm{ml} \mathrm{kg}^{-1} \mathrm{~min}^{-1}$ with a further increase of work rate; a respiratory gas exchange ratio of 1.15 ; and a plateauing of heart rate with further increase of work-rate.

\section{Submaximal exercise bout}

The treadmill was set at $0 \%$ slope, and a speed judged to elicit $80 \%$ of the treadmill maximal oxygen intake ${ }^{17}$. Expired gas was collected and analysed throughout, and heart rate was recorded every second minute. Perceived exertion was rated in the final minute of exercise, using the ten-point scale of Borg ${ }^{18}$.

\section{Blood sampling}

Blood samples were collected from the antecubital vein at rest immediately before and $5 \mathrm{~min}$ and $30 \mathrm{~min}$ after the 30-min acute bout of submaximal exercise. Measurements included cortisol, creatine kinase, lymphocyte proliferation, percentages of $T$ and $B$ cells, helper/suppressor cell ratios, and immunoglobulin synthesis. Analytic techniques are detailed elsewhere ${ }^{19}$.

\section{Serum cortisol determinations}

Serum cortisol was measured by an automated fluorescent polarizing spectrometer assay (Abbott TDx Cortisol assay (Abbott Laboratories, Missisauga, Ontario, Canada)).

\section{Serum creatine kinase determinations}

Serum creatine kinase was determined using Boehringer-Mannheim kits (Boehringer-Mannheim, Montreal, Quebec, Canada). A mixture of creatine phosphate and ADP yields ATP and creatine, and in the presence of glucose, reduces NADP to NADPH. The absorbance at $365 \mathrm{~nm}$ is increased in proportion to creatine kinase activity.

\section{Mitogen stimulation of peripheral lymphocytes}

Mononuclear cells were separated by centrifugation with Sepracell-MN, (Sepratech, Oklahoma City, USA) a colloidal silica-based medium. They were then resuspended in an appropriate medium and checked to ensure cell viability, using the trypan blue exclusion technique ${ }^{20}$. Peripheral blood monocytes were incubated in the presence of an appropriate range of concentrations of two plant lectins (phytohaemaglutinin, PHA, 10-20 $\mu \mathrm{g} \mathrm{ml}^{-1}$, and concanavalin $\mathrm{A}$, Con- $\mathrm{A}, 1-4 \mu \mathrm{g} \mathrm{ml}^{-1}$ ) that are specific mitogenic stimulants of $T$ cell proliferation. Responses to PHA are reputedly resistant to cortisone levels, while responses to Con-A are suppressed by cortisone ${ }^{21}$. 
At $48 \mathrm{~h}$, the cells were pulsed for $24 \mathrm{~h}$ with $1.0 \mu \mathrm{Ci}$ of radioactive (methyl-3H) thymidine, and after $72 \mathrm{~h}$ the cells were harvested on to glass fibre filters. The filters were subsequently placed in scintillation fluid and counted by a liquid scintillation counter. Results were expressed as the difference in counts between the stimulated cultures and non-stimulated controls.

\section{Lymphocyte populations}

The mononuclear cell suspension was divided and marked by $20 \mu \mathrm{l}$ volumes of monoclonal antibodies specific for $\mathrm{T}$ cells (Anti-Leu-4, $\mathrm{CD}^{+}{ }^{+}$), B cells (Anti-Leu-16, $\mathrm{CD}^{+} 0^{+}$), helper cells (Anti-Leu-3a, $\mathrm{CD}^{+}$) and suppressor cells (Anti-Leu-2a, $\mathrm{CD} 8^{+}$).

The marked cells were resuspended and passed through a flow cytometer, using light at $650 \mathrm{~nm}$ to activate the fluorochrome-labelled monoclonal antibodies. The ascites mouse Ig does not bind to any of the specific sites for the human monoclonal antibodies, and the area under the measurable light profile for this antigen was thus used as a control to subtract from the histograms seen with the specific antibodies.

\section{Immunoglobulin synthesis}

Cell suspensions were mixed with equal volumes of lyophilized pokeweed mitogen, incubated for 7 days, centrifuged and then frozen for IgG and IgM analysis by enzyme-linked immunosorbant assay. An IgG or IgM peroxidase conjugate was added to each well of the culture plate. After $1 \mathrm{~h}$ of incubation and further washing, an ortho-phenyldiamine $2 \mathrm{HCl}$ substrate catalysed by $0.5 \%$ hydrogen peroxide was added to generate a yellow colour that could be measured against an appropriate calibration curve at a wavelength of $492 \mathrm{~nm}$.

\section{Statistical analysis}

Repeated measures analyses of variance were used in conjunction with post hoc contrast analyses to assess differences over time. Paired $t$ tests were utilized to assess the effects of acute exercise (comparing pre-exercise with post-exercise values at a given testing session). The null hypothesis was rejected at $P$ $<0.05$.

\section{Results}

\section{Subject characteristics}

The subjects were typical long-distance runners. Their body mass (mean(s.d.) $66.1(4.7) \mathrm{kg}$ ) was low in relation to their height (mean(s.d.) $176.8(4.4) \mathrm{cm}$ ), and they had relatively little subcutaneous fat (sum of biceps, triceps, subscapular, suprailiac and medial calf skinfolds (mean(s.d.) 26.1(6.0) $\mathrm{mm}$ )). The relative maximal oxygen intake was much higher than in the typical well-trained man of 29 years (initial mean(s.d.) $65.3(4.9) \mathrm{ml} \mathrm{kg}^{-1} \mathrm{~min}^{-1}$ ), and the personal best $10-\mathrm{km}$ times of mean(s.d.) $31 \mathrm{~min} 43 \mathrm{~s}(1 \mathrm{~min}$ $38 \mathrm{~s})$ confirmed that these were indeed highly trained runners. Despite the narrow range of interindividual performances, the personal best race times were quite closely correlated with the individuals' relative maximal oxygen intakes $(r=-0.86, P<0.0014)$.

All subjects were training hard for distance events when first recruited, their initial weekly running distances averaging $98.8(22.0) \mathrm{km}$.

\section{Modification of training plan}

Each runner was consulted individually to establish a schedule of heavy training that could be sustained for the 3-week experimental period without incurring gross orthopaedic injuries. In most cases, subjects elected to increase both the intensity of exercise and the weekly running distance, but subjects 4 and 7 restricted themselves to an increase of training distance (Table 1).

The consensus of the group was that they could sustain a $25 \%$ increment of training volume throughout the 3 weeks. In fact, the activity questionnaires showed that the weekly distance had been increased

Table 1. Training plans adopted by individual subjects during the initial 3 weeks (B1), during the 3 weeks of beavy training (HT), and during the 3 weeks of repeated baseline training (B2)

\begin{tabular}{|c|c|c|c|c|c|c|c|c|}
\hline Subject & $\begin{array}{c}\text { B1 } \\
\text { training } \\
\text { distance } \\
\left(\mathrm{km}^{\text {week }}{ }^{-1}\right)\end{array}$ & $\begin{array}{c}H T \\
\text { training } \\
\text { distance } \\
\left(\mathrm{km}^{-1} \text { week }^{-1}\right)\end{array}$ & $\begin{array}{c}\text { B2 } \\
\text { training } \\
\text { distance } \\
\left(\mathrm{km}^{-1} \text { week }^{-1}\right)\end{array}$ & $\begin{array}{c}\% \\
\text { increase } \\
B 1 \text { to } H T\end{array}$ & $\begin{array}{c}\text { B1 } \\
\text { training } \\
\text { volume }\end{array}$ & $\begin{array}{c}\stackrel{5}{5}{ }^{2}{ }^{20} \\
\text { training } \\
\text { volume }\end{array}$ & $\begin{array}{l}\text { B2 } \\
\text { training } \\
\text { volume }\end{array}$ & $\begin{array}{c}\% \\
\text { increase } \\
\text { B1 to } H T\end{array}$ \\
\hline $\begin{array}{r}1 \\
2 \\
3 \\
4 \\
5 \\
6 \\
7 \\
8 \\
9 \\
10\end{array}$ & $\begin{array}{r}103.7 \\
97.0 \\
107.8 \\
77.2 \\
81.6 \\
96.5 \\
109.4 \\
148.7 \\
69.3 \\
96.5\end{array}$ & $\begin{array}{l}121.1 \\
108.3 \\
131.5 \\
126.4 \\
135.0 \\
130.7 \\
135.8 \\
193.1 \\
121.0 \\
100.2\end{array}$ & $\begin{array}{r}106.2 \\
61.1 \\
70.7 \\
64.6 \\
98.8 \\
102.4 \\
89.2 \\
107.7 \\
65.0 \\
93.1\end{array}$ & $\begin{array}{r}17 \\
12 \\
22 \\
64 \\
65 \\
35 \\
24 \\
30 \\
75 \\
4\end{array}$ & $\begin{array}{l}5769 \\
5268 \\
5761 \\
3981 \\
3948 \\
5765 \\
5078 \\
6696 \\
3996 \\
5742\end{array}$ & $\begin{array}{l}7102 \\
6315 \\
7112 \\
6520 \\
6640 \\
7802 \\
6486 \\
9016 \\
7081 \\
5953\end{array}$ & $\begin{array}{l}5964 \\
3419 \\
3558 \\
3415 \\
5040 \\
5803 \\
4242 \\
5011 \\
3795 \\
5391\end{array}$ & $\begin{array}{r}23 \\
20 \\
23 \\
64 \\
68 \\
35 \\
28 \\
35 \\
77 \\
4\end{array}$ \\
\hline Mean(s.d.) & $98.8(22.0)$ & $130.3(24.9)$ & $85.9(18.6)$ & $35(25)$ & $5200(943)$ & $7003(877)$ & 4564(996) & $38(24)$ \\
\hline
\end{tabular}

The training volume was approximated as a simple multiple of the daily training distance and a speed-related assessment of the oxygen cost. For example, if an athlete ran a distance of $16 \mathrm{~km}$ at a pace of $4.47 \mathrm{~m} \mathrm{~s}^{-1}$, the estimated oxygen cost would be $57.1 \mathrm{ml} \mathrm{kg}$ (Reference 17), and the training volume would be $16 \times 57.1$, or 913.6 units. If there were five such sessions in a week, the total volume
score for that individual would be $913.6 \times 5$, or 4568 units. 
by $35 \%$, and since most subjects also had some increase of speed over the same route, the estimated training volume was increased by an average of $38 \%$. Nine of the ten runners achieved at least a $20 \%$ increase of training volume throughout the 3-week period. The largest increase (subject 9) is a little misleading, in that he began the study at a level some $30 \mathrm{~km}$ week $^{-1}$ below his normal schedule. Subject 10 had achieved a $21 \%$ increase by the end of the second week, but then complained of excessive tiredness, and managed only five abbreviated workouts in the third experimental week. If his data are excluded, the remaining subjects demonstrated a $41 \%$ average increase of training volume. Subjects 2, 3, 4, 7 and 8 also reported sustained tiredness at the end of the experimental period, and thus undertook less than their normal training volume during the recovery period. In terms of both performance and symptomatic responses, we would conclude that at least six of the ten subjects were beginning to show signs of excessive training.

\section{Objective signs of excessive training}

Subjects were asked to record waking heart rates on a daily basis throughout the 3 weeks of heavy training and the subsequent 3-week recovery period. There was a small and not statistically significant trend to an increment during the period of heavy training, and a decrease in the first week of recovery, but even in the most fatigued subject (subject 4) the increment from normal training (mean 51.5 beats $\mathrm{min}^{-1}$ ) to the third week of heavy training (53.4 beats $\left.\min ^{-1}\right)$ was less than 2 beats $\min ^{-1}$. Plainly, a change of this order, even if statistically significant, would have little value as an early warning of excessive training.

Subjects were also asked to record the quality and the quantity of their daily sleep. In the eight individuals who kept adequate records, there was no evidence of a change of quality or quantity of sleep either during the period of heavy training or during the subsequent recovery period.

The Profile of Mood States (Figure 1) suggested that heavy training led to some changes in the initial

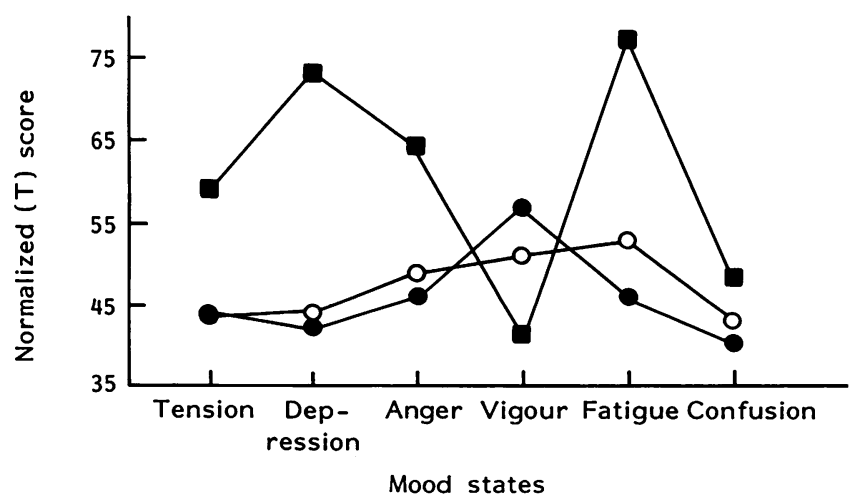

Figure 1. Impact of 3 weeks of increased training upon the Profile of Mood States. Average values for ten endurance athletes initially running $70-100 \mathrm{~km}$ week $^{-1}$. Data obtained by Morgan ${ }^{29}$ after heavy training of a swimmer is also presented. O, Before HT; $O$, immediately after HT; Morgan's data. (HT = 3-week period of heavy training) classical 'iceberg' profile. There was an increase of global disturbance (that is, a displacement of the summated mood ratings away from the normal standardized score, $P=0.03$ ), with a significant increase of fatigue $(P=0.03)$ and a significant decrease of vigour $(P=0.02)$. Although not statistically significant, there was also a trend for other negative mood states (depression, anger and confusion) to increase in response to heavy training. The subsequent recovery period was associated with a return towards baseline scores for both the global mood rating and scores on the five negative mood scales. However, scores for vigour remained significantly below the initial level.

None of the runners developed any clinical injuries during their 3-week period of heavy training. Subject 10 sensed the onset of a cold, which became manifest immediately after the period of heavy training. Subject 6 felt in good health when tested, yet within 3 days of completing the heavy training, he also developed an acute rhinoviral infection. Subject 9 indicated that he felt as if he were developing a cold at his final laboratory visit. He was diagnosed 2 weeks later as having exercise-induced asthma, although he had not complained of respiratory problems in the years before the study.

\section{Impact on aerobic power}

On average, the heavy training did not lead to any gains of maximal aerobic power (Table 2). In all except three subjects, the difference of maximal oxygen intake between the two visits was less than $5 \%$. The largest decrease of $5.9 \%$ was seen in a subject who was highly fatigued (subject 4), whereas the largest increase of $8.2 \%$ was seen in a subject who ran his personal best time on day 11 of the heavy training schedule. The decrease of peak heart rate, although small, approached statistical significance, being shown by nine of the ten subjects.

There was little difference in the oxygen cost of running during the acute bout of submaximal exercise among visits 2, 3 and 5 (Table 3), although there was a small but statistically significant decrease of the heart rate response to the acute bout of exercise immediately following the period of heavy training.

Table 2. Influence of 3-week period of increased training upon maximal performance - comparison of initial with experimental values

\begin{tabular}{|c|c|c|}
\hline Variable & Mean(s.d.) & Range \\
\hline $\begin{array}{l}\text { Initial } \dot{V}_{\mathrm{O}_{2} \max }\left(\mathrm{ml} \mathrm{kg}^{-1} \min ^{-1}\right) \\
\text { Experimental } \dot{\mathrm{V}}_{2 \max }\left(\mathrm{ml} \mathrm{kg}^{-1} \min ^{-1}\right) \\
\text { Initial max heart rate }\left(\text { beats min } \mathrm{min}^{-1}\right)\end{array}$ & $\begin{array}{l}65.3(4.9) \\
65.1(4.5) \\
186(9.0)\end{array}$ & $\begin{array}{l}58.4-72.9 \\
58.7-70.8 \\
172-204\end{array}$ \\
\hline $\begin{array}{l}\text { Experimental max heart rate } \\
\quad\left(\text { beats } \min ^{-1}\right) \\
\text { Initial treadmill time (s) } \\
\text { Experimental tradmill time (s) }\end{array}$ & $\begin{array}{l}182(8.0) \\
650(83) \\
664(90)\end{array}$ & $\begin{array}{l}174-200 \\
530-802 \\
546-823\end{array}$ \\
\hline
\end{tabular}

A paired two-tailed $t$ test suggests a trend to a reduction of maximal heart rate after the period of increased training $(P=$ 0.058) 
Table 3. Comparison of the oxygen cost of submaximal exercise $\left(\mathrm{ml} \mathrm{kg}^{-1} \mathrm{~min}^{-1}\right)$ and heart rates (HR, beats min $\left.{ }^{-1}\right)$ initially (B1), after 3 weeks of heavy training (HT), and after 3 weeks of repeated baseline training (B2)

\begin{tabular}{|c|c|c|c|c|c|c|c|}
\hline \multirow[t]{2}{*}{ Subject } & \multirow{2}{*}{$\begin{array}{c}\text { Treadmill } \\
\text { speed } \\
\left(m s^{-1}\right)\end{array}$} & \multicolumn{2}{|c|}{$B 1$} & \multicolumn{2}{|c|}{$H T$} & \multicolumn{2}{|c|}{$B 2$} \\
\hline & & Submax $\dot{V}_{o_{2}}$ & Submax HR & Submax $\dot{V}_{\mathrm{O}_{2}}$ & Submax HR & Submax $\dot{V}_{O_{2}}$ & Submax HR \\
\hline 1 & 4.47 & 54.9 & 152 & 53.6 & 150 & 53.0 & 152 \\
\hline 2 & 4.69 & 48.6 & 165 & 51.7 & 169 & 50.6 & 170 \\
\hline 3 & 4.58 & 50.8 & 162 & 47.6 & 156 & 50.8 & 170 \\
\hline 4 & 4.47 & 50.7 & 165 & 58.9 & 161 & 50.9 & 170 \\
\hline 6 & 4.47 & 55.6 & 155 & 55.2 & 156 & 52.8 & 156 \\
\hline 7 & 4.25 & 50.7 & 167 & 49.9 & 161 & 50.3 & 168 \\
\hline 8 & 4.36 & 47.6 & 156 & 45.2 & 149 & 46.6 & 161 \\
\hline 9 & 4.81 & 53.6 & 150 & 56.1 & 148 & 53.3 & 147 \\
\hline 10 & 4.92 & 54.8 & 181 & 50.7 & 172 & 48.4 & 170 \\
\hline Mean(s.d.) & & $51.6(3.0)$ & (A) $162.8(10.0)$ & $51.9(4.1)$ & $\left(B^{*}\right)$ 158.7(8.4) & $50.3(2.5)$ & (A) 161.1(8.2) \\
\hline
\end{tabular}

* B differs from $A$ ( $P<0.05$ for significant intergroup difference) by application of repeated measures analysis in conjunction with Duncan's Multiple Range Test.

Table 4. Response of serum cortisol to 30 min of exercise at $80 \%$ of maximal oxygen intake at the end of 3 weeks of normal training, after 3 weeks of heavy training, and after 3 weeks of return to baseline training (all values nmol ${ }^{-1}$ ). Data obtained at consistent times of day, immediately before exercise (Pre) and $5 \mathrm{~min}$ after exercise bout (latter shown as $\Delta$ value)

\begin{tabular}{|c|c|c|c|c|c|c|}
\hline \multirow[t]{2}{*}{ Subject } & \multicolumn{2}{|c|}{ Initial } & \multicolumn{2}{|c|}{ Heavy training } & \multicolumn{2}{|c|}{ Recovery } \\
\hline & Pre & $\Delta$ & Pre & $\Delta$ & Pre & $\Delta$ \\
\hline 1 & 229 & 226 & 300 & 22 & - & - \\
\hline 2 & 519 & -122 & 508 & 14 & 378 & -98 \\
\hline 3 & - & - & 397 & -95 & 334 & -49 \\
\hline 4 & 217 & 85 & 212 & 141 & - & - \\
\hline 5 & 506 & 222 & 619 & -64 & 445 & 110 \\
\hline 6 & 297 & 82 & - & - & 201 & 75 \\
\hline 7 & 306 & -41 & 305 & -47 & 240 & -71 \\
\hline 8 & 470 & -44 & 456 & -97 & 545 & -108 \\
\hline 9 & 222 & 47 & 268 & -37 & 110 & 41 \\
\hline 10 & 295 & 156 & 327 & 32 & 319 & 38 \\
\hline Mean(s.d.) & $340(124)$ & $68^{*}(121)$ & $377(130)$ & $-15(76)$ & 321(139) & $-8(84)$ \\
\hline
\end{tabular}

$* P<0.05$; two-tailed paired $t$ test

\section{Serum cortisol levels}

The resting cortisol levels (Table 4) were quite high at all three visits $(2,3$ and 4$)$. Resting values tended to be higher after heavy training and a little lower after resumption of baseline training, but these differences were not statistically significant.

At the first laboratory visit, the acute bout of submaximal treadmill exercise led to a small increase of serum cortisol $(P<0.05)$. However, submaximal exercise no longer caused a significant increase after heavy training. Complete datasets were only available on seven of the ten subjects. In these individuals, the cortisol response to the acute bout of exercise at visit 3 was similar to that seen at visit 1 , although because of the small sample size the visit 3 response was not statistically significant.

\section{Serum creatine kinase levels}

The resting creatine kinase (CK) levels were high in all three training conditions (Table 5). The submaximal treadmill challenge led to a further increase of CK at all three laboratory visits. Datasets were complete for only nine subjects, the increments immediately after exercise being 25,27 and 20 units $1^{-1}$ respectively for the three experimental conditions. Two of three subjects who did not show an acute exercise CK response began the experiment with particularly high resting CK values $\left(277\right.$ and 293 units $1^{-1}$ respectively, relative to anticipated normal ceilings of 100 units $1^{-1}$ ).

Table 5. Response of serum creatine kinase to acute 30 -min bout of exercise at $80 \%$ of maximal oxygen intake after 3 weeks of normal training, after 3 weeks of heavy training, and after 3 weeks of return to baseline training. Mean(s.d.) of data (units $\left.\right|^{-1}$ )

\begin{tabular}{llll}
\hline Sampling time & Initial & Heavy training & Recovery \\
\hline Resting & $155(94)$ & $176(97)$ & $126(94)$ \\
5 min after exercise & $167(93)^{*}$ & $203(110)^{*}$ & $146(111)^{*}$ \\
30 min after exercise & $187(96)$ & $193(104) \dagger$ & $141(105)$ \\
\hline
\end{tabular}

* Differ significantly from the corresponding resting value $(P<$ 0.05 ), using repeated measures analysis in conjunction with post hoc contrast comparisons

+ Significantly lower than the corresponding value measured 5 min after exercise $(P<0.05)$, using repeated measures analysis in conjunction with post hoc contrast comparisons 
Table 6. Effects of acute 30-min bout of exercise at $80 \%$ of maximal oxygen intake upon mitogen-induced peripheral blood mononuclear cell proliferation. Data for phytohaemagglutinin (PHA) and concanavalin A (Con-A), expressed as a percentage change of scintillation count rate, after 3 weeks of normal training (B1), 3 weeks of heavy training (HT), and 3 weeks of return to baseline training (B2)

\begin{tabular}{|c|c|c|c|c|c|c|}
\hline \multirow[t]{3}{*}{ Subject } & \multicolumn{6}{|c|}{ Percentage change in scintillation count } \\
\hline & \multicolumn{3}{|c|}{ PHA } & \multicolumn{3}{|c|}{ Con-A } \\
\hline & B1 & $H T$ & $B 2$ & B1 & $H T$ & B2 \\
\hline 1 & -10.4 & -32.2 & -12.6 & -12.9 & -24.6 & -17.6 \\
\hline 2 & -3.2 & -53.5 & 30.3 & -26.5 & -43.0 & 55.5 \\
\hline 3 & - & -22.8 & -14.0 & - & -21.8 & -6.7 \\
\hline 4 & 3.6 & -30.7 & -20.0 & 14.6 & -13.7 & -10.0 \\
\hline 5 & -44.5 & -18.7 & -15.3 & -42.0 & -30.7 & -16.1 \\
\hline 6 & -18.4 & -16.3 & -24.7 & -26.2 & -19.2 & -12.2 \\
\hline 7 & -7.9 & 9.4 & 13.6 & -13.5 & 16.6 & 21.1 \\
\hline 8 & 10.7 & 15.4 & -35.8 & 17.4 & 28.3 & -18.6 \\
\hline 9 & 55.4 & -4.9 & 26.3 & 111.2 & 17.4 & 10.2 \\
\hline 10 & -21.5 & -25.1 & -25.5 & -12.2 & -26.4 & -5.5 \\
\hline Mean(s.d.) & $-4.0(27)$ & $-17.9 *(20)$ & $-7.8(23)$ & 1.1(45) & $-11.7(24)$ & $0.0(23)$ \\
\hline
\end{tabular}

${ }^{*} P<0.05 ;$ two-tailed paired $t$ test

\section{Rating of perceived exertion}

The initial rating of the acute bout of submaximal exertion was of mean(s.d.) 3.55(1.42) (range 2.0-6.5) units. The nearest semantic descriptions on the modified Borg scale are moderate ( 3 units) and somewhat strong (4 units) of exertion. Scores were closely comparable after the period of heavy training (mean(s.d.) 3.65(0.94) units) and after the 3-week return to baseline training $(3.50(0.58)$ units).

\section{Immune responses}

Many previous studies have been content to count lymphocyte numbers. However, this approach ignores the known impact of stressors upon the relative proportions of the various cell types, their ability to proliferate and ingest bacteria, and their ability to secrete antibodies.

\section{Mitogen-induced cell proliferation}

Mitogen-induced cell proliferation is a useful overall in vitro measure of cell-mediated immune function $^{20-23}$. The acute bout of submaximal exercise had no consistent impact upon cell proliferation while subjects were following a normal training plan (Table 6). The three individuals who initially were covering the shortest training distances relative to their usual routine (and who were thus the most rested) showed a positive PHA (average $+\mathbf{8 1 . 4 \%}$ ) and Con-A (average $+53.1 \%$ ) response to the acute bout of submaximal exercise, whereas the remaining six subjects with complete data showed some acute suppression of the response to both PHA $(-46.7 \%)$ and Con-A (-24.9\%). Any effect was quite transient, and at $30 \mathrm{~min}$ after exercise the average response for all nine subjects was greater than under resting conditions $(+6.2 \%$ for PHA, and $+14.2 \%$ for Con-A).

Immediately after the 3 weeks of heavy training, the resting blood samples showed increased cell proliferation $(+24.6 \%$ for PHA, $+32.2 \%$ for Con-A), the latter change being statistically significant $(P<$ $0.05)$. However, relative to the new resting values, the submaximal test exercise induced a small but statistically significant reduction in response to PHA, with a similar but statistically insignificant trend for Con-A (Table 6). Resting responses remained higher than initial values after 3 weeks of return to baseline training (for PHA, $P=0.034$, for Con-A, $P=0.024$ ), but as initially, the average response to the mitogens was unchanged by the test bout of acute submaximal exercise.

\section{Lymphocyte populations}

Three primary categories of lymphocyte are recognized, T cells, B cells and null cells. A combination of monoclonal antibodies and flow cytometry allows differentiation of these various cell types, and of subpopulations of $T$ cells.

Both $\mathrm{T}$ and $\mathrm{B}$ lymphocyte percentages tended to decrease $5 \mathrm{~min}$ after exercise, with recovery $30 \mathrm{~min}$ after exercise, these changes being most marked immediately after heavy training (see Table 7 for statistically significant changes).

Table 7. Effects of an acute 30 -min bout of exercise at $80 \%$ of maximal oxygen intake upon lymphocyte populations after 3 weeks of normal training, 3 weeks of heavy training, and 3 weeks of repeated baseline training. Data collected before exercise bout (Pre), and at $5 \mathrm{~min}(+5)$ and $30 \mathrm{~min}(+30)$ after exercise

\begin{tabular}{|c|c|c|c|c|c|c|}
\hline \multirow{3}{*}{$\begin{array}{l}\text { Training } \\
\text { regimen }\end{array}$} & \multicolumn{6}{|c|}{ Percentage of total lymphocyte count } \\
\hline & \multicolumn{3}{|c|}{ T lymphocytes } & \multicolumn{3}{|c|}{ B lymphocytes } \\
\hline & Pre & +5 & +30 & Pre & +5 & +30 \\
\hline $\begin{array}{l}\text { Initial } \\
\text { Heavy training } \\
\text { Recovery }\end{array}$ & $\begin{array}{c}64.7 \\
a 62.6 \\
a 55.2^{*}\end{array}$ & $\begin{array}{r}57.5 \\
\text { b54.3 } \\
49.9\end{array}$ & $\begin{array}{r}61.0 \\
61.1 \\
b 62.2\end{array}$ & $\begin{array}{r}4.65 \\
4.64 \\
\text { a3.51 }\end{array}$ & $\begin{array}{l}4.02 \\
3.77 \\
2.89\end{array}$ & $\begin{array}{r}5.01 \\
5.28 \\
\text { b4.68 }\end{array}$ \\
\hline
\end{tabular}

All values are shown as percentages of the total lymphocyte count as seen in the peripheral blood mononuclear cell suspension. Horizontal items for a given lymphocyte type with differing letter prefixes differ significantly from each other $(P<0.05)$ by Duncan's Multiple Range Test.

* Vertically, significantly different $(P<0.05)$ using repeated measures ANOVA and applying Duncan's Multiple Range Test 
Table 8. Response of helper and suppressor cells to an acute bout of $30 \mathrm{~min}$ of exercise at $80 \%$ of maximal oxygen intake after 3 weeks of normal training, 3 weeks of heavy training, and 3 weeks of return to baseline training. Data collected before the exercise bout (Pre), and at $5 \mathrm{~min}(+5)$ and $30 \mathrm{~min}(+30)$ after exercise

\begin{tabular}{lrrr}
\hline Variable & Initial & $\begin{array}{c}\text { Heavy } \\
\text { training }\end{array}$ & Recovery \\
\hline Helper cells (\%) & & & \\
$\quad$ Pre & $\mathrm{a} 38.2$ & 33.2 & $\mathrm{b30.5}$ \\
$\quad+5$ & 31.6 & 30.2 & 26.7 \\
$\quad+30$ & 34.5 & 32.0 & 29.6 \\
Suppressor cells (\%) & 16.6 & $\mathrm{a} 18.0$ & $\mathrm{~b} 12.5$ \\
$\quad$ Pre & 19.2 & 17.6 & 14.5 \\
$\quad+5$ & 14.0 & 14.2 & 11.6 \\
$\quad+30$ & & & \\
Helper:suppressor ratio & 2.91 & $\mathrm{a2} .05$ & $\mathrm{a3.49*}$ \\
$\quad$ Pre & 1.84 & 1.89 & $\mathrm{b2.53}$ \\
$\quad+5$ & 2.74 & $\mathrm{b3.17}$ & 3.98 \\
$\quad+30$ & & \\
\hline
\end{tabular}

Horizontally, a differs from $b(P<0.05)$ using repeated measures ANOVA and Duncan's Multiple Range test

Vertically, a differs from $b(P<0.05)$ using repeated measures ANOVA and applying Duncan's Multiple Range test

Horizontally, * is significantly different from both initial and heavy training values $(P<0.05)$.

The resting percentage of helper cells tended to diminish after heavy training, and their number was further decreased after return to baseline training (see Table 8 for statistically significant changes). In contrast, the resting percentage of suppressor cells was increased after heavy training, with corresponding changes in the helper:suppressor cell ratio. Under all three conditions, the helper:suppressor cell ratio tended to diminish $5 \mathrm{~min}$ after exercise, with a full recovery or even an overshoot $30 \mathrm{~min}$ after exercise (Table 8).

\section{Mitogen-induced immunoglobulin synthesis}

Pokeweed mitogen is a known activator of both $\mathrm{T}$ and $B$ cells, and is thus commonly used to assess the synthesis of immunoglobulins by the $B$ cells $^{24}$.

Table 9. Effect of an acute $30-\mathrm{min}$ bout of exercise at $80 \%$ of maximal oxygen intake upon pokeweed mitogen-induced IgG synthesis immediately after 3 weeks of normal training, after 3 weeks of heavy training, and after 3 weeks of return to baseline training. Concentrations in $\mathrm{ng} \mathrm{ml}^{-1}$. Data collected before exercise bout (Pre), and at $5 \mathrm{~min}(+5)$ and $30 \mathrm{~min}(+30)$ after exercise

\begin{tabular}{lccc}
\hline $\begin{array}{l}\text { Training } \\
\text { regimen }\end{array}$ & \multicolumn{3}{c}{ Timing of sample } \\
\cline { 2 - 4 } & Pre & +5 & +30 \\
\hline Initial & ab644 $(n=10)$ & $913(n=8)$ & $701(n=9)$ \\
Heavy training & a537 $(n=9)$ & $488(n=10)$ & $* 904(n=9)$ \\
Recovery & b884 $(n=10)$ & $847(n=10)$ & $828(n=10)$
\end{tabular}

Means with the same letter prefix do not differ significantly from each other $(P>0.05)$ using repeated measures ANOVA and applying Duncan's Multiple Range test

* Data differ significantly from the other two blood sampling times immediately after heavy training $(P<0.05)$
Table 10. Influence of an acute bout of exercise at $80 \%$ of maximal oxygen intake on pokeweed mitogen-induced synthesis of IgM after 3 weeks of normal training, after 3 weeks of heavy training, and after 3 weeks of return to baseline training. All values expressed as $\mathrm{ng} \mathrm{ml}^{-1} \mathrm{lgM}$. Data collected before exercise bout (Pre) and at $5 \mathrm{~min}(+5)$ and $30 \mathrm{~min}(+30)$ after exercise

\begin{tabular}{lccc}
\hline \multirow{2}{*}{$\begin{array}{l}\text { Training } \\
\text { regimen }\end{array}$} & \multicolumn{3}{c}{ Timing of sample } \\
\cline { 2 - 4 } & Pre & +5 & +30 \\
\hline Initial & a730 $(n=10)$ & $765(n=8)$ & $836(n=9)$ \\
Heavy training & a585 $(n=10)$ & $589(n=10)$ & $* 908(n=10)$ \\
Recovery & b1178 $(n=10)$ & $1052(n=10)$ & $1098(n=10)$ \\
\hline
\end{tabular}

Means with the same letter prefix do not differ significantly from each other $(P>0.05)$ using repeated measures ANOVA and applying Duncan's Multiple Range Test

* Value tends to significant difference from the other two blood samples taken following heavy training session $(P<0.07)$

Resting data showed a trend to decreased IgG production at the end of heavy training, with an increment over the 3-week return to baseline training (see Table 9 for statistically significant changes). The submaximal test exercise tended to increase IgG production at the initial visit. After the period of heavy training, the increment of IgG synthesis was delayed until $30 \mathrm{~min}$ after the test exercise, whereas data after the 3-week recovery period showed little effect of the acute submaximal test exercise.

Resting IgM synthesis was greater after the 3-week recovery period than either initially $(P<0.03)$ or after the period of heavy training $(P<0.01)$. Exerciseinduced changes in IgM synthesis (see Table 10 for statistically significant changes) followed a somewhat similar pattern to that seen with IgG. After the period of heavy training, production was increased $30 \mathrm{~min}$ after the test exercise, but there was little response to the test exercise after the 3-week recovery period.

\section{Discussion}

\section{Evidence of excessive training}

Ethical limitations constrained the increase of training that our investigation was able to encourage 3 weeks of exercise to self-selected perceived tolerance levels is not a long period of heavy training. Moreover, subjects did not face the added stress of major competition, and they had the option of tapering or ceasing the activity if fatigued. None of the subjects was clinically ill, and in most the peak aerobic power was unchanged. They cannot thus be considered as pathologically 'over-trained'. Nevertheless, the sudden and sustained $38 \%$ increase of training volume was substantial for a group of athletes who were already running $70-100 \mathrm{~km}$ week $^{-1}$, and the symptoms reported by six of the ten participants suggest that the majority of our sample had indeed reached or was close to the threshold of excessive training which most coaches would like to detect. The development of respiratory symptoms in three of the ten subjects is a further indication that training was at the upper limit of the desirable from the viewpoint of immune function. On the other hand, stable readings for maximal oxygen intake and 
ratings of perceived exertion, the absence of clinical injuries and the minor nature of changes in serum creatine kinase all confirm that the crest of performance had not been greatly surpassed.

Traditional indicators ${ }^{1}$ were not particularly helpful in assessing whether the training was excessive, perhaps in part because of limitations in these markers, and in part because the subjects realized that the heavy training was at their own volition and was not threatening their competitive performance. The resting heart rate ${ }^{3}$ showed a suspicion of some increase, but even if tachycardia is accepted as a valid index, it would be hard to base recommendations to moderate training upon a 2 beats $\min ^{-1}$ increment in an individual's waking heart rate. Likewise, sleep patterns showed no obvious disturbance with heavy training. Some inference of increased stress might be drawn from the increase of resting cortisol levels after the 3 weeks of heavy training, and the decreased cortisol response to an acute bout of submaximal exercise might suggest that such training had surpassed the optimal or eu-stress level ${ }^{25}$. Barron et al. ${ }^{26}$ earlier suggested that hypothalamic failure, as evidenced by a reduced cortisol response to hypoglycaemia, was a useful indicator of 'overtraining', but their subjects were ill, unlike the present group. Moreover, cortisol estimations are technically difficult to complete, and are notoriously susceptible to the immediate emotional responses of the subject ${ }^{27}$. Thus, such measures are unlikely to provide a useful marker of excessive training in an athlete who is becoming concerned about deteriorating performance, but has not yet developed gross clinical 'overtraining'.

In keeping with the earlier observations of Morgan et al. ${ }^{28}$, the one simple measure which gave a consistent response to the heavy training was the Profile of Mood States (POMS). This is a rapidly completed procedure, and is well accepted in sports psychology ${ }^{29}$. The one disadvantage of POMS is that the intent of the questions is fairly obvious to the respondent.

\section{Changes of immune function}

Do the various measures of immune function change with heavy training, and if so do they offer a useful alternative measure of training that is becoming excessive $^{11,14}$ ? The group as a whole showed some small changes of both cellular and humoral immunity in response to the period of heavy training, in terms of both their resting status and their response to a standard submaximal exercise challenge. However, despite careful attempts to standardize techniques ${ }^{15}$, there was considerable interindividual and intraindividual variation in scores for the various tests, to the point that it would be difficult to place great reliance upon routine data obtained on any single individual. Moreover, the measures of cellular and humoral immune function required highly sophisticated test equipment, and are extremely time-consuming. Although the findings have considerable theoretical interest, it seems unlikely that they will be applied to the evaluation of training status in other than occasional international competitors within the forseeable future.

\section{Implications for exercise prescription}

Do the group changes in immune function have wider implications for moderation in the choice of an exercise prescription? There have been earlier suggestions that both regular athletic training and single bouts of prolonged exercise, such as a 2-h ski race, can depress immune function ${ }^{10,12,14}$, with potentially adverse consequences for resistance to infection, neoplasms and autoimmune diseases. On the other hand, cross-sectional comparisons have shown that a reasonable training programme is quite compatible with maintenance of normal immune function ${ }^{14,30-33}$, and longitudinal studies have demonstrated an enhancement of resting immune function with the moderate training of sedentary subjects ${ }^{14,34,35}$. In keeping with these latter reports, our data suggest that adverse responses are unlikely when subjects continue the pattern of activity to which they are habituated. Furthermore, well-trained individuals such as our sample of distance runners can apparently tolerate a sudden, sustained and substantial increase over their normal pattern of training with only minor, transient and largely subclinical disturbances of immune function. In our experiments, resting immune function was apparently normalized within 3 weeks of a return to the pattern of habitual training, and even at the peak of the heavy training episode, most of the adverse reactions to an acute submaximal exercise challenge disappeared within $30 \mathrm{~min}$ of ceasing exercise.

The development of respiratory symptoms in three of the ten subjects may reflect a transient increase of susceptibility to viral infections, of the type previously postulated in athletes $s^{6-9,12}$, but, in apparent contrast to some earlier studies of less well-trained populations ${ }^{36-40}$, the average decrease in helper:suppressor cell ratio at no stage dropped to the critical level of 1.5 where the response to polyclonal $\mathrm{T}$ cell mitogens is impaired.

\section{Conclusions}

We conclude that well-trained distance runners can increase their habitual training plan by a substantial margin of around $40 \%$ without developing symptoms and signs of 'overtraining'. In agreement with earlier reports, resting pulse rate, sleep patterns and hormonal changes do not provide a useful early warning that the peak of performance has been passed, but the POMS does show a consistent pattern of loss of vigour and fatigue during heavy training. Sophisticated tests of immune function show that heavy training induces some small, transient disturbances both at rest and during acute bouts of vigorous submaximal exercise, but the required measurements are time-consuming and costly. Moreover, although the observed changes of immune response seem to indicate that training is becoming excessive, they are likely to have only a minor influence on overall immune function. 


\section{Acknowledgements}

This research was supported in part by the US Olympic Committee. Our sincere thanks are due to Dr Paul Corey and Dr Pang Shek for their contributions at many points in this study. We also wish to thank the Defence and Civil Institute of Environmental Medicine and the Faculty of Medicine, University of Toronto, Canada, for the use of special laboratory facilities.

\section{References}

1 Ryan AJ, Burke ER, Falsetti HL et al. Overtraining of athletes: round table. Phys Sportsmed 1983; 11: 93-110.

2 Kuipers $\mathrm{H}$, Keizer HA. Overtraining in elite athletes: review and directions for the future. Sports Med 1988; 6: 79-92.

3 Dressendorfer $\mathrm{RH}$, Wade $\mathrm{CE}$, Scaff JH. Increased morning heart rate in runners: a valid sign of overtraining. Phys Sportsmed 1985; 13: 1215-18.

4 Wenger H, Smith B, MacKenzie D. Progress report on a longitudinal overstress study involving the Canadian National Rowing Team. Paper presented at the Annual Meeting of the Canadian Association of Sport Sciences, Ottawa, 1986.

5 Costill DL Physiological alterations during periods of training overload. Med Sci Sports Exerc 1987; 19: S77.

6 Jokl E. The immunological status of athletes. J Sports Med 1974; 14: 165-7.

7 Douglas DJ, Hanson PG. Upper respiratory infections in the conditioned athlete. Med Sci Sports Exerc 1978; 10: 55.

8 Costill DL. Inside Running. Indianapolis, Indiana, USA: Benchmark Press, 1986.

9 Weinstein L. Poliomyelitis - a persistent problem. N Engl J Med 1973; 288: 370-2.

10 Tomasi TB, Trudeau FB, Czerwinski D, Erredge S. Immune parameters in athletes before and after strenuous exercise. J Clin Immunol 1982; 2: 173-8.

11 MacKinnon LT, Tomasi TB. Immunology of exercise. Ann Sports Med 1986; 3: 1-4.

12 Niemann DC, Johanssen LM, Lee JW, Arabatzis K. Infectious episodes in runners before and after the Los Angeles marathon. J Sports Med Phys Fitness 1990; 30: 316-28.

13 Simon HB. Exercise and infection. Phys Spotsmed 1987; 15: $134-41$.

14 Shephard RJ, Verde TJ, Thomas SG, Shek P. Physical activity and the immune system. Can J Sport Sci 1991; 16: 163-85.

15 Verde TJ. The Effects of Acute Exercise and Heavy Training on Immune Function in Elite Athletes. PhD Thesis, University of Toronto, Canada, 1990.

16 McNair DM, Lorr M, Droppleman LF. Profile of Mood States Manual. San Diego, California, USA: Educational and Industrial Testing Service, 1971.

17 Dill DB. Oxygen used in horizontal and grade walking and running on the treadmill. J Appl Physiol 1965; 20: 19-22.

18 Borg GV. Psychological bases of perceived exertion. Med Sci Sports Exerc 1982; 14: 377-87.

19 Verde T, Thomas S, Shek P, Shephard RJ. Immune responses and increased training of the elite athlete. Eur J Appl Physiol 1992; (in press).

20 Mishell BB, Shiigi SM. Selected Methods in Cellular Immunology. San Francisco, California, USA: WH Freeman, 1980.

21 Fauci AS, Dale DC. The effect of in vivo hydrocortisone on subpopulations of human lymphocytes. I Clin Invest 1974; 53: 240-6.

22 Bloom BR. In vitro approaches to the mechanism of cell mediated immune reactions. Adv Immunol 1971; 13: 101-206.

23 Claman HN. The biology of the immune response. JAMA 1987; 285: 2834-40.

24 DeShazo RD, Lopez M, Salvaggio JE. Use and interpretation of diagnostic immunologic laboratory tests. JAMA 1987; 258: 3011-31.

25 Selye H. The Stress of Life. New York, USA: McGraw Hill, 1956.

26 Barron JL, Noakes TD, Levy W, Smith C, Millar RP. Hypothalamic dysfunction in overtrained athletes. I Clin Endocrinol Metab 1985; 60: 803-6.

27 Shephard RJ, Sidney K. Effects of physical exercise on plasma growth hormone and cortisol levels in human subjects. Exerc Sport Sci Reo 1975; 3: 1-30.

28 Morgan WP, Brown DR, Raglin JS, O'Connor PJ, Ellickson KA. Psychological monitoring of overtraining and staleness. Br J Sports Med 1987; 21: 107-14.

29 Morgan WP. Selected psychological factors limiting performance: a mental health model. In: DH Clarke and HM Eckert, eds. Limits of Human Performance. Champaign, Illinois, USA: Human Kinetics, 1985.

30 Busse WW, Anderson CL, Hanson PG, Folts JD. The effect of exercise on the granulocyte response to isoproterenol in the trained athlete and the untrained individual. J Allergy Clin Immunol 1981; 65: 358-64.

31 Green RL, Kaplan SS, Rabin BS, Stanitski CL, Zdziarski U. Immune function in marathon runners. Ann Allergy 1981; 47: 73-5.

32 Hanson PG, Flaherty DK. Immunological responses to training in conditioned runners. Clin Sci 1981; 60: 225-8.

33 Oshida Y, Yamanouchi K, Hayamizu S, Sato Y. Effect of acute physical exercise on lymphocyte subpopulations in trained and untrained subjects. Int J Sports Med 1988; 9: 137-40.

34 Soppi E, Varjo P, Eskola J, Laitinen LA. Effect of strenuous physical stress on circulating lymphocyte number and function before and after training. J Clin Lab Immunol 1982; 8: 43-6.

35 Watson RR, Moriguchi S, Jackson JC, Werner L, Wilmore JH, Freund BJ. Modification of cellular immune functions in humans by endurance training during $\beta$-adrenergic blockade with atenolol or propranolol. Med Sci Sports Exerc 1986; 18: 95-100.

36 Hedfors E, Holm G, Ivansen M, Wahren J. Physiological variation of blood lymphocyte reactivity: T-cell subsets, immunoglobulin production, and mixed lymphocyte reactivity. Clin Immunol Immunopath 1983; 27: 9-14.

37 Landmann RMA, Muller FB, Peini $\mathrm{CH}$, Wesp $\mathrm{M}$, Erne $\mathrm{P}$ Buhler FR. Changes of immunoregulatory cells induced by psychological and physical stress: relationship to catecholamines. Clin Exp Immunol 1984; 58: 127-35.

38 Brahmi Z, Thomas JE, Park M, Dowdeswell IRG. The effect of acute exercise on natural killer cell activity of trained and sedentary human subjects. J Clin Immunol 1985; 5: 321-8.

39 Berk LS, Nieman D, Tan SA et al. Lymphocyte subset changes during acute maximal exercise. Med Sci Sports Exerc 1986; 18: 706.

40 Lewicki R, Tchorzewski H, Majewska E, Nowak Z, Baj Z Effect of maximal physical exercise on T-lymphocyte subpopulations and on interleukin 1 (IL1) and interleukin 2 (IL2) production in vitro. Int J Sports Med 1988; 9: 114-17. 